\title{
Combating chronic T-cell exhaustion
}

\author{
"Strategies to overcome exhaustion effectively, as a means to improve \\ immunotherapy for chronic infection or cancer, will likely need to include both \\ blockade of extrinsic cellular and molecular signals as well as intrinsic \\ programming of T-cell exhaustion."
}

\section{KEYWORDS: cancer $\approx$ cytokines $\approx$ exhaustion $\approx$ immunotherapy $\approx$ infection $\approx$ inhibition - T cell $n$ tolerance}

T cells are currently being employed for the treatment of patients with persistent viral infections or cancer in many immunotherapeutic approaches, including provision of cytokines, therapeutic vaccines or adoptive transfer of virus- or tumorspecific $T$ cells [1-6]. Despite the different strategies used to enhance T-cell responses to persisting pathogens or malignant cells, a common limitation is tolerization of $\mathrm{T}$ cells due to prolonged antigen stimulation. Such exhaustion of $\mathrm{CD}^{+}$ or $\mathrm{CD} 8{ }^{+} \mathrm{T}$-cell responses has been observed in a number of clinical and experimental infections in humans, nonhuman primates and mice, including in HIV, hepatitis $\mathrm{C}$ virus and Plasmodium infection, as well as in melanoma, Epstein-Barr virus-induced tumors and ovarian cancer. This suggests that exhaustion is a conserved mechanism for limiting T-cell immunopathology during pathogen persistence [7-13]. In order to enhance the effectiveness of T-cell-based immunotherapeutic strategies, it is necessary to define and overcome the molecular mechanisms that promote and maintain T-cell exhaustion.

\section{The spectrum of exhaustion}

T-cell exhaustion is not an all-or-nothing phenomenon; during chronic infection, T cells progressively lose effector functions, with the degree of dysfunction directly correlating with the levels of virus or antigen present [14]. Initially, T cells lose the ability to proliferate in response to antigen stimulation, concomitant with loss of production of the T-cell growth factor IL-2. Subsequently, $\mathrm{T}$ cells lose the ability to secrete inflammatory cytokines such as TNF. The highest levels of T-cell exhaustion correlate with impaired killing of infected target cells and reduced production of antiviral cytokines including IFN- $\gamma$ [15]. It is now clear that the varying levels of T-cell exhaustion are regulated both by extrinsic mechanisms such as inhibition by Treg subsets and signaling via inhibitory cytokines, as well as by intrinsic mechanisms including loss of expression of cytokines/cytokine receptors and increased expression of surface inhibitory receptors $[16,17]$.

\section{Qui tacet consentit versus the Red Queen hypothesis}

T-cell exhaustion, defined by an inability to control the infection or tumor cells and lack of effector function in in vitro assays, does not inherently differentiate between a scenario in which $T$ cells are continuously exerting their effector function in vivo but have not had sufficient time to recover prior to analysis, versus one in which programmed T-cell tolerance results in lack of in vivo effector function. In the former case, the Red Queen hypothesis ("It takes all the running you can do, to keep in the same place") would describe exhaustion as the result of continuous exertion of effector functions in vivo, and implies that the 'exhausted' $T$ cells maintain residual functions and continue to exert some selective pressure on the infection or tumor [18]. This is supported by selection of T-cell escape viruses during the chronic phase of infection in HIV patients, despite exhaustion of virus-specific $T$ cells [19]. In addition, regulation of virus-specific T-cell function in these settings by extrinsic factors such as Tregs, IL-10 and TGF- $\beta$ would suggest that these are required to suppress ongoing T-cell effector responses [20-22].

Conversely, exhaustion is also probably due to intrinsic programming of tolerance in $T$ cells $[23,24]$. In this case, exhausted $T$ cells do not retain function in vivo and their silence

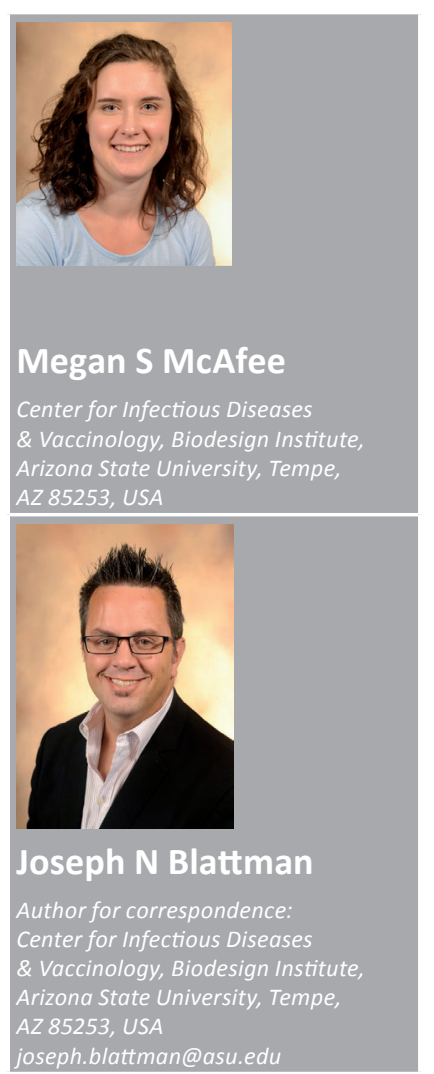

Future
Medicine $\mathrm{fs}$ par of 
implies consent (Latin: qui tacet consentit) to the infection or tumor in order to limit immunopathology. Exhausted T cells do exhibit unique gene expression patterns compared with either effector or memory $\mathrm{T}$ cells, suggesting that intrinsic regulation of $\mathrm{T}$-cell exhaustion is an important mechanism for maintaining T-cell tolerance [25]. Recently, we have helped to show that $\mathrm{T}$ cells are programmed to return to their exhausted state even after transient rescue of function and in the absence of continued antigen recognition [23].

\section{Overcoming extrinsic regulation of exhaustion}

Both Tregs and cytokines, including IL-10 and TGF- $\beta$, have been shown to suppress T-cell function and contribute to T-cell exhaustion during chronic viral infections and tumor persistence [17]. Depletion of Foxp $3^{+} \mathrm{CD} 4^{+}$Tregs in mouse models of chronic viral infection can increase the functional activity of the antiviral $\mathrm{CD}^{+} \mathrm{T}$ cells and result in better control of the virus [22]. Cytokines produced by Tregs, and potentially by other cells, in the setting of prolonged antigenspecific T-cell responses can also attenuate T-cell function either indirectly by suppressing production of proinflammatory cytokines or directly by inhibition of $\mathrm{CD}^{+}{ }^{+}$and $\mathrm{CD} 8{ }^{+} \mathrm{T}$-cell proliferation [20]. Antibody blockade of IL-10 signaling during chronic viral infection has been shown to result in improved T-cell function and enhanced clearance of disseminated virus in mouse models of infection $[20,26,27]$. Similarly, expression of TGF- $\beta$ is increased during chronic viral infection and abrogation or blockade of TGF- $\beta$ signals in vivo during virus infection or tumor growth results in improved retention of T-cell function and accelerated clearance of virus or tumor $[21,28]$.

\section{"...it is likely that strategies blocking multiple inhibitory pathways will be more efficacious in the treatment of chronic infection or cancer..."}

Overcoming suppression of T-cell function by extrinsic factors would appear to be relatively straightforward, involving the application of strategies similar to those utilized in experimental models that employ depleting Treg subsets or antibody/drug blockade of cytokine signals in order to promote T-cell function [20,22,26]. However, one concern with regard to using such strategies to modulate T-cell exhaustion is the induction of autoimmunity to self-antigens, as these pathways are also important for limiting auto-reactive responses [29]. Thus, more work needs to be done to address the relative importance of these regulatory mechanisms after establishment of exhaustion and to test whether the primary role of these extrinsic factors is to suppress new T-cell responses.

\section{Overcoming intrinsic regulation of exhaustion}

The differential gene-expression profile in exhausted cells, compared with that of naive, effector or memory CD ${ }^{+}$T-cell populations [25], results in decreased expression of proteins that may be important for maintaining continued cell function, including cytokines and cytokine receptors [16], as well as increased expression of inhibitory receptors on the surface of exhausted T cells. It is now clear that the loss of T-cell effector function correlates with increased expression of multiple cell surface inhibitory proteins including PD-1, LAG-3, Tim-3, CD160, 2B4 and CTLA-4 $[17,30]$. PD-1 is highly expressed on activated $T$ cells, particularly during chronic infection, and antibody blockade of PD-1 can significantly enhance T-cell function during chronic virus infection in both humans and mice [7,31-33]. LAG-3 is a negative regulator of $\mathrm{T}$ cells, expressed on both activated $\mathrm{CD}^{+}$and $\mathrm{CD}^{+} \mathrm{T}$ cells, which regulates the ability of these cells to proliferate in response to antigens $[9,34]$. Although it is still not clear which effector functions the different inhibitory proteins regulate, it is likely that strategies blocking multiple inhibitory pathways will be more efficacious in the treatment of chronic infection or cancer due to enhancement of multiple T-cell effector functions. For example, targeting both the PD-1/PD-L1 pathway and LAG-3 or Tim-3 can further induce recovery of T-cell function during chronic infection or cancer $[9,13,35]$. Similarly, blockade of PD-1/PD-L1 while simultaneously blocking IL-10 signals can promote viral clearance in experimental mouse models [26].

\section{T-cell programming}

Exhausted T cells undergo slow proliferation in vivo. Therefore, daughter $\mathrm{T}$ cells must either retain the exhaustion 'program' or quickly reestablish exhaustion after division. In light of recent experiments showing that exhausted cells are programmed to return to their exhausted state after transient rescue, even in the absence of continued antigen stimulation, it seems highly likely that epigenetic regulation of exhaustion is an important strategy for maintaining exhaustion [23]. This may be due to inheritance of 
specific transcription factors or miRNAs that control the transcriptional profile observed in exhausted $\mathrm{T}$ cells. For example, miR-181a was found to be highly expressed in tolerant cells but expressed at lower levels in rescued cells [23]. In addition, different patterns of DNA methylation at specific gene loci in exhausted versus effector $\mathrm{T}$ cells may contribute to the exhaustion program. For example, demethylation of the $P d c d 1$ gene regulatory region may help to maintain expression of PD-1 in exhausted cells [24].

Conversely, lymphopenia-induced proliferation has been shown to bypass the molecular program of tolerance and at least temporarily rescue the function of exhausted $T$ cells [23]. Similarly, provision of exogenous cytokines such as IL-2, IL-7 and/or IL-15 to promote T-cell proliferation can overcome some types of T-cell exhaustion [16,36-38]. What is even more striking is that $T$ cells can be rescued multiple times from exhaustion. This suggests either that some exhaustion mechanisms are not programmed into cells but rather are acquired shortly after division, or that extensive division is able to overcome epigenetic regulation of T-cell exhaustion. However, once the proliferative signal is removed, the $\mathrm{T}$ cells regain tolerance and lose functionality, even in the absence of antigens. While there are many drawbacks to employing lymphopenia-induced proliferation to enhance
T-cell immunotherapeutic approaches, this strategy has been used in cancer patients, resulting in extensive expansion of infused tumor-infiltrating lymphocytes [39].

\section{Conclusion \& future perspective}

Multiple extrinsic and intrinsic molecular mechanisms contribute to T-cell exhaustion and likely regulate different functional properties of $\mathrm{T}$ cells. Strategies to overcome exhaustion effectively, as a means to improve immunotherapy for chronic infection or cancer, will likely need to include both blockade of extrinsic cellular and molecular signals as well as intrinsic programming of T-cell exhaustion. Moreover, rescue from exhaustion has so far been transient, and it is likely that T-cell-based immunotherapies for infection or cancer will require multiple interventions in order to maintain T-cell functionality.

\section{Financial \& competing interests disclosure}

The authors have no relevant affiliations or financial involvement with any organization or entity with a financial interest in or financial conflict with the subject matter or materials discussed in the manuscript. This includes employment, consultancies, honoraria, stock ownership or options, expert testimony, grants or patents received or pending, or royalties.

No writing assistance was utilized in the production of this manuscript.

\section{References}

1 Rosenberg SA, Yang JC, Sherry RM et al. Durable complete responses in heavily pretreated patients with metastatic melanoma using T-cell transfer immunotherapy. Clin. Cancer Res. 17(13), 4550-4557 (2011).

2 Einsele H, Hebart H. CMV-specific immunotherapy. Hum. Immunol. 65(5), 558-564 (2004).

3 Van Der Burg SH, Arens R, Melief CJ. Immunotherapy for persistent viral infections and associated disease. Trends Immunol. 32(3), 97-103 (2011).

4 Fuller DH, Rajakumar P, Che JW et al. Therapeutic DNA vaccine induces broad $\mathrm{T}$ cell responses in the gut and sustained protection from viral rebound and AIDS in SIV-infected rhesus macaques. PLoS ONE 7(3), e33715 (2012).

5 Lang K, Weiner DB. Immunotherapy for HCV infection: next steps. Expert Rev. Vaccines 7(7), 915-923 (2008).

6 Riddell SR, Greenberg PD, Overell RW et al. Phase I study of cellular adoptive immunotherapy using genetically modified
CD8 ${ }^{+}$HIV-specific T cells for HIV seropositive patients undergoing allogeneic bone marrow transplant. The Fred Hutchinson Cancer Research Center and the University of Washington School of Medicine, Department of Medicine, Division of Oncology. Hum. Gene Ther. 3(3), 319-338 (1992).

7 Day CL, Kaufmann DE, Kiepiela P et al. PD-1 expression on HIV-specific T cells is associated with T-cell exhaustion and disease progression. Nature 443(7109), 350-354 (2006).

8 Fourcade J, Sun Z, Benallaoua M et al. Upregulation of Tim-3 and PD-1 expression is associated with tumor antigen-specific $\mathrm{CD} 8^{+}$ $\mathrm{T}$ cell dysfunction in melanoma patients. J. Exp. Med. 207(10), 2175-2186 (2010).

9 Matsuzaki J, Gnjatic S, Mhawech-Fauceglia P et al. Tumor-infiltrating NY-ESO-1-specific $\mathrm{CD} 8^{+} \mathrm{T}$ cells are negatively regulated by LAG-3 and PD-1 in human ovarian cancer. Proc. Natl Acad. Sci. USA 107(17), 7875-7880 (2010).

10 Fourcade J, Sun Z, Pagliano O et al. CD8(+) $\mathrm{T}$ cells specific for tumor antigens can be rendered dysfunctional by the tumor microenvironment through upregulation of the inhibitory receptors BTLA and PD-1. Cancer Res. 72(4), 887-896 (2012).

11 Bengsch B, Seigel B, Ruhl M et al. Coexpression of PD-1, 2B4, CD160 and KLRG1 on exhausted HCV-specific CD8 ${ }^{+}$ $\mathrm{T}$ cells is linked to antigen recognition and T cell differentiation. PLoS Pathog. 6(6), e1000947 (2010).

12 Yang ZZ, Grote DM, Ziesmer SC et al. IL-12 upregulates TIM-3 expression and induces $\mathrm{T}$ cell exhaustion in patients with follicular B cell non-Hodgkin lymphoma. J. Clin. Invest. 122(4), 1271-1282 (2012).

13 Butler NS, Moebius J, Pewe LL et al. Therapeutic blockade of PD-L1 and LAG-3 rapidly clears established blood-stage Plasmodium infection. Nat. Immunol. 13(2), 188-195 (2012).

14 Wherry EJ, Blattman JN, Murali-Krishna K, Van Der Most R, Ahmed R. Viral persistence alters CD8 T-cell immunodominance and tissue distribution and results in distinct stages of functional impairment. J. Virol. 77(8), 4911-4927 (2003). 
15 Kim PS, Ahmed R. Features of responding $\mathrm{T}$ cells in cancer and chronic infection. Curr. Opin Immunol. 22(2), 223-230 (2010).

16 Ingram JT, Yi JS, Zajac AJ. Exhausted CD8 $T$ cells downregulate the IL-18 receptor and become unresponsive to inflammatory cytokines and bacterial co-infections. PLoS Pathog. 7(9), e1002273 (2011).

17 Wherry EJ. T cell exhaustion. Nat. Immunol. 12(6), 492-499 (2011)

18 Carroll L. Through the Looking Glass, and What Alice Found There. Macmillian, London, UK (1871).

19 Barouch DH, Kunstman J, Glowczwskie J et al. Viral escape from dominant simian immunodeficiency virus epitope-specific cytotoxic T lymphocytes in DNA-vaccinated rhesus monkeys. J. Virol. 77(13), 7367-7375 (2003).

20 Blackburn SD, Wherry EJ. IL-10, T cell exhaustion and viral persistence. Trends Microbiol. 15(4), 143-146 (2007).

21 Tinoco R, Alcalde V, Yang Y, Sauer K, Zuniga EI. Cell-intrinsic transforming growth factor-beta signaling mediates virus-specific $\mathrm{CD} 8{ }^{+} \mathrm{T}$ cell deletion and viral persistence in vivo. Immunity 31(1), 145-157 (2009).

22 Punkosdy GA, Blain M, Glass DD et al. Regulatory T-cell expansion during chronic viral infection is dependent on endogenous retroviral superantigens. Proc. Natl Acad. Sci. USA 108(9), 3677-3682 (2011).

23 Schietinger A, Delrow JJ, Basom RS, Blattman JN, Greenberg PD. Rescued tolerant CD8 $\mathrm{T}$ cells are preprogrammed to reestablish the tolerant state. Science 335(6069), 723-727 (2012).

24 Youngblood B, Oestreich KJ, Ha SJ et al. Chronic virus infection enforces demethylation of the locus that encodes PD-1 in antigen-specific CD8(+) T cells. Immunity 35(3), 400-412 (2011).

25 Wherry EJ, Ha SJ, Kaech SM et al. Molecular signature of $\mathrm{CD} 8^{+} \mathrm{T}$ cell exhaustion during chronic viral infection. Immunity 27(4), 670-684 (2007).

26 Brooks DG, Ha SJ, Elsaesser H, Sharpe AH, Freeman GJ, Oldstone MB. IL-10 and PD-L1 operate through distinct pathways to suppress T-cell activity during persistent viral infection. Proc. Natl Acad. Sci. USA 105(51), 20428-20433 (2008).

27 Ejrnaes M, Filippi CM, Martinic MM et al. Resolution of a chronic viral infection after interleukin-10 receptor blockade. J. Exp. Med. 203(11), 2461-2472 (2006).

28 Ganapathy V, Ge R, Grazioli A et al. Targeting the transforming growth factor-beta pathway inhibits human basal-like breast cancer metastasis. Mol. Cancer 9, 122 (2010).

29 Goodnow CC, Sprent J, Fazekas De St Groth B, Vinuesa CG. Cellular and genetic mechanisms of self tolerance and autoimmunity. Nature 435(7042), 590-597 (2005).

30 Blackburn SD, Shin H, Haining WN et al. Coregulation of CD8 ${ }^{+} \mathrm{T}$ cell exhaustion by multiple inhibitory receptors during chronic viral infection. Nat. Immunol. 10(1), 29-37 (2009).

31 Sharpe AH, Wherry EJ, Ahmed R, Freeman GJ. The function of programmed cell death 1 and its ligands in regulating autoimmunity and infection. Nat. Immunol. 8(3), 239-245 (2007).

32 Blackburn SD, Crawford A, Shin H, Polley A, Freeman GJ, Wherry EJ. Tissue-specific differences in PD-1 and PD-L1 expression during chronic viral infection: implications for CD8 T-cell exhaustion. J. Virol. 84(4), 2078-2089 (2010)

33 Nakamoto N, Cho H, Shaked A et al. Synergistic reversal of intrahepatic HCVspecific CD8 $\mathrm{T}$ cell exhaustion by combined PD-1/CTLA-4 blockade. PLoS Pathog. 5(2), e1000313 (2009).

34 Workman CJ, Cauley LS, Kim IJ, Blackman MA, Woodland DL, Vignali DA. Lymphocyte activation gene-3 (CD223) regulates the size of the expanding $\mathrm{T}$ cell population following antigen activation in vivo. J. Immunol. 172(9), 5450-5455 (2004).

35 Jin HT, Anderson AC, Tan WG et al. Cooperation of Tim-3 and PD-1 in CD8 T-cell exhaustion during chronic viral infection. Proc. Natl Acad. Sci. USA 107(33), 14733-14738 (2010).

36 Pellegrini M, Calzascia T, Toe JG et al. IL-7 engages multiple mechanisms to overcome chronic viral infection and limit organ pathology. Cell 144(4), 601-613 (2011).

37 Blattman JN, Grayson JM, Wherry EJ, Kaech SM, Smith KA, Ahmed R. Therapeutic use of IL-2 to enhance antiviral T-cell responses in vivo. Nat. Med. 9(5), 540-547 (2003).

38 Teague RM, Sather BD, Sacks JA et al. Interleukin- 15 rescues tolerant $\mathrm{CD} 8{ }^{+} \mathrm{T}$ cells for use in adoptive immunotherapy of established tumors. Nat. Med. 12(3), 335-341 (2006).

39 Dudley ME, Yang JC, Sherry R et al. Adoptive cell therapy for patients with metastatic melanoma: evaluation of intensive myeloablative chemoradiation preparative regimens. J. Clin. Oncol. 26(32), 5233-5239 (2008). 